\title{
ADVANTAGES OF A TIME SERIES ANALYSIS USING WAVELET TRANSFORM AS COMPARED WITH A FOURIER ANALYSIS
}

\author{
Patrik SLEZIAK ${ }^{1 *}$, Kamila HLAVČOVÁ ${ }^{1}$, Ján SZOLGAY
}

\section{Abstract}

The paper presents an analysis of changes in the structure of the average annual discharges, average annual air temperature, and average annual precipitation time series in Slovakia. Three time series with lengths of observation from 1961 to 2006 were analyzed. An introduction to spectral analysis with Fourier analysis (FA) is given. This method is used to determine significant periods of a time series. Later in this article a description of a wavelet transform (WT) is reviewed. This method is able to work with non-stationary time series and detect when significant periods are presented. Subsequently, models for the detection of potential changes in the structure of the time series analyzed were created with the aim of capturing changes in the cyclical components and the multiannual variability of the time series selected for Slovakia. Finally, some of the comparisons of the time series analyzed are discussed. The aim of the paper is to show the advantages of time series analysis using WT compared with FT. The results were processed in the $R$ software environment.
Address

1 Department of Land and Water Resources Management, Faculty of Civil Engineering, Slovak University of Technology, Radlinského 11, 813 68, Bratislava, Slovak Republic

* Corresponding author: patrik.sleziak@stuba.sk

\section{Key words}

- Statistical analysis,

- Fourier analysis,

- wavelet transform

\section{INTRODUCTION}

Many years have been dedicated to searching for new ways to improve traditional techniques of analyzing changes in the structure of time series. A recent possible approach for solving this task is a detailed analysis of data from past periods. In this field several methods are used; the most well-known are spectral analysis, trend analysis, and autocorrelation analysis.

These techniques have been used by several authors, for example, Brázdil (1986), who compared time series of precipitation and discharges and their fluctuations combined with solar activity. Pekárová (2000) analyzed the cyclical components of the discharges of Slovak rivers. Pekárová et al. (2008) focused on analyses of time series. Several good works cover the theory of Fourier analysis. For a revision of the classical theory, we recommend consulting Weaver (1989). This reference also covers the discrete Fourier transform (FT). A compre- hensive reference for the discrete FT, which is from a more computational point of view, is found in Briggs \& Henson (1995). For more detail, Gomes \& Velho (1997) is recommended.

Sabo (2012) used wavelet analysis (WA) to identify whether there is any relation between the Danube and Moravia rivers and solar activity. According to his article, some significant periods have been revealed. Sleziak (2013) provided an introduction to spectral analysis and applied WT to analyze the average annual discharges of selected Slovak rivers. An understandable introduction to wavelet analysis is also provided by Daubechies et al. (1992) and Torrence and Compo (1998). The works of Labat et al. (2001) and Labat (2005, 2006, 2008), should also be mentioned. Labat et al. (2001) introduces wavelet analysis and then applies this technique to determine the relationship between precipitation and runoff. Labat (2008) used this technique to analyze the annual discharges of the world's largest rivers. Szolgayová et al. (2013) used wavelet analysis in their work and 
applied this technique to determine the dependence of the time series of monthly discharges, precipitation and air temperatures on the Danube river. Szolgayová et al. (2014) used wavelet analysis for modelling and forecasting of daily discharges on the Danube river.

Wavelet analysis can be used in several areas. For example, Kumar et al. (1997) used this technique to detect signals in geophysics, and Prokop et al. (1996) detected nonstationary components in geological time series based on wavelets. Liu et al. (2005) used WA to analyze the relationships between Length-Of-Day (LOD) variations and the El Nino/Southern Oscillation (ENSO) on interannual scales. This study quantitatively shows timescale-dependent correlations and phase shifts between LOD variations and the ENSO. Grinsted et al. (2004) applied WA to geophysical time series. This technique was used for examining relationships in the time frequency space between two time series. The article demonstrated how phase angle statistics can be used to gain confidence in causal relationships between times. Biswas (2014) examined the similarity in the spatial patterns of soil water storage and their characteristic landscape positions for variable soil depths and time on a field scale. Li et al. (2014) performed wavelet analyses to examine the relationships between the Air Pollution Index and several metodological factors. Mokhov et al. (2012) used wavelet coherence (WC) to detect the relationship between changes in the global surface air temperature with different natural and anthropogenic factors. Feng et al. (2011) analyzed the temporal variability of water discharges and sediment loads of the Yellow River into the sea from 1950-2008. Zhang et al. (2014), used 146 years (1865-2010) of streamflow data to investigate the changes in the streamflow of the Yangtze River in China. WA analyses were used to test the changes in annual streamflows.

The introduction refers to the results of existing studies and presents some features and results that make WT a suitable method for modeling changes in the structure of time series. The issue focuses on an analysis and evaluation of the cyclical components of average annual discharges, average annual air temperatures, and average annual precipitation using the FA and WT methods. The aim of the paper is to show the advantages of time series analysis using WT compared with FT and also show the cyclical components and multi-annual variability of a time series.

\section{METHODOLOGY}

In this paper, the authors focused on a description of two methods: Fourier analysis and wavelet transform. These techniques provide powerful tools for analyzing time series. From this perspective, it is interesting for the authors to compare these techniques and show the differences between them. The structure of this work can be divided into the following four steps:

- Creation of a database of time series of average annual discharges, air temperatures, and the precipitation of selected gauging stations.

- Analysis of annual data sets using the Fourier analysis and wavelet transform methods. The data were processed in the $\mathrm{R}$ software environment (R Development Core Team, 2011) using the WaveletCo package (Tian and Cazelles, 2011) for the wavelet transform and the pgam package (Junger and Ponce de Leon, 2011) for the periodograms of the Fourier analysis. The plotting of the wavelet and scaling coefficients were processed by package wavelets (Aldrich, 2013).

Development of appropriate models for the description of the characteristics of the time series observed.

- Analysis of the structural changes in hydrometeorological time series. Finally, some of the comparisons of the time series analyzed are discussed.

\subsection{Fourier analysis versus wavelet transform}

In science and engineering, the process of the decomposition of a series or signal $x(t)$ into a sum of sinusoidal components is called Fourier analysis. The decomposition process itself is called Fourier transform. It identifies different frequency sinusoids and their respective amplitudes or energy within a given time series. The Fourier transform $\hat{x}(\omega)$ of a continuous signal $x(t)$ is defined as:

$$
\hat{x}(\omega)=\int_{-\infty}^{\infty} x(t) e^{-i \omega t} d t
$$

The transform is often given a more specific name, which depends upon the domain and other properties of the function being transformed. Moreover, the original concept of the Fourier analysis has been extended over time to apply to more and more general situations, and the general field is often known as harmonic analysis. FA is more efficient in the study of signals that do not suffer sudden variations over time. These signals are called stationary signals (Bloomfield, 2000).

FA is used to determine significant cyclical components in the analysis of signals. It is important to mention its two major disadvantages:

- The method assumes that a signal is stationary over time; this means that at a certain time, its properties do not change. For example, during the annual discharges of the Danube river, this would mean that during the whole period, the behavior of the annual discharges did not significantly change (Sabo, 2012).

- FA can only identify individual periods of cyclic components and not their position over time. This means that the results of the analysis only identify periods which are present at the time of the signal (Sabo, 2012).

On the contrary, wavelet transform deals with both problems in a very effective way. It is able to work with non-stationary time series and also able to detect when significant periods are present. WT is an integral transformation, which allows for obtaining time-frequency information about a signal. It is applied to obtain the position and duration of a phenomenon. It is based on the search for wavelet coefficients, which, for a given time and range, measure the similarity of the original signal with a subsidiary (transformed) wave (Cazelles et al. 2008).

An important role in wavelet transform is played by the mother wavelet $\varphi(t)$. It is necessary for it to have the following properties:

a) the wavelet must have a mean value of 0 :

$$
\int_{-\infty}^{\infty} \varphi(t) d t=0
$$

b) the wavelet must have a final amount of energy:

$$
\int_{-\infty}^{\infty}|\varphi(t)|^{2} d t=1
$$

c) it must have the condition of an inverse transform, where $\hat{\varphi}(t)$ denotes the Fourier transform of the function $\varphi(t)$.

$$
\int_{-\infty}^{\infty} \frac{|\hat{\varphi}(t)|^{2}}{\omega} d \omega<\infty
$$

A good example of a mother wavelet is the morlet wavelet (Fig. 1). It is possible to transform it in two ways: stretching it (changing its shape) and moving it at the time (along the horizontal axis). Transformed mother wavelets are then called "subsidiary". We can describe it in more detail: The mother morlet wavelet is moved over time from left to right after the signal (Figs. 2, 3). Subsequently, for each specific time, the wavelet coefficients are calculated, which 
means they show the extent to which the subsidiary wavelet coincides with the frequency of the signal. In the next step we change parameter $\alpha$; thus the wavelet is stretched, and then we pass it through the whole signal and observe the similarity in the times. We continue for all the values of parameter $\alpha$. The subsidiary is more similar to the original wavelet signal on some scales, and at a particular time, the value of the wavelet coefficients is higher (Sabo, 2012).

For a visualization of wavelet coefficients, a scalogram is used (Fig. 10). The vertical axis denotes a period ( $\alpha$-cyclical components), and the horizontal axis denotes the time ( $\tau-$ the duration of the signal). The size of the wavelet coefficient is expressed as the intensity of a color.

The scalogram provides the following important information:

- On the right side of the scalogram, we can see the global wavelet spectrum. It is an averaged scalogram considering the whole period of time. Its advantage is that we can easily identify the periods found.

- A section of the scalogram is identified in the shape of a cupola This is an area behind which the counting of the wavelet coefficients is problematic. Edge effects may appear

- Around the intense colors is a zone shown by a white line, which symbolizes a significant period (Sabo, 2012).

\subsubsection{Wavelet spectrum and significance levels}

To determine significance levels for wavelet spectra, one first needs to choose an appropriate background spectrum. For many phenomena, an appropriate background spectrum is white noise (with a flat Fourier spectrum) or red noise (increasing power with a decreasing frequency). These spectra are used to establish a null hy-

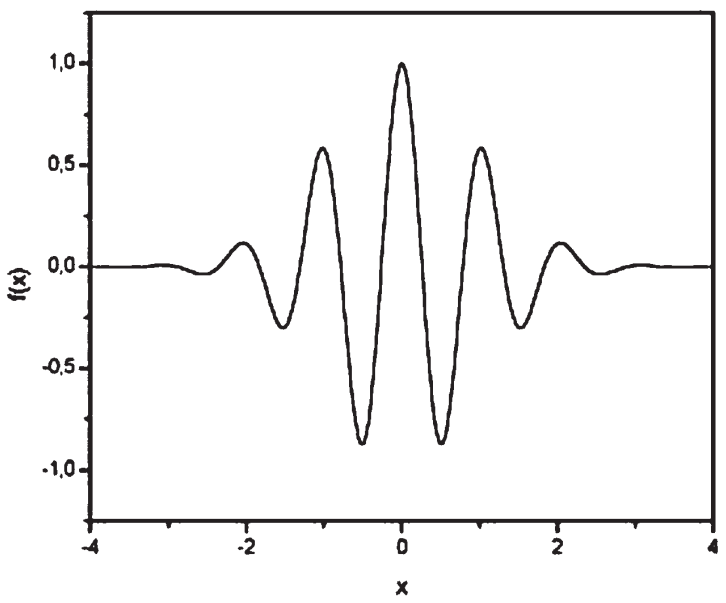

Fig. 1 Morlet mother wavelet.

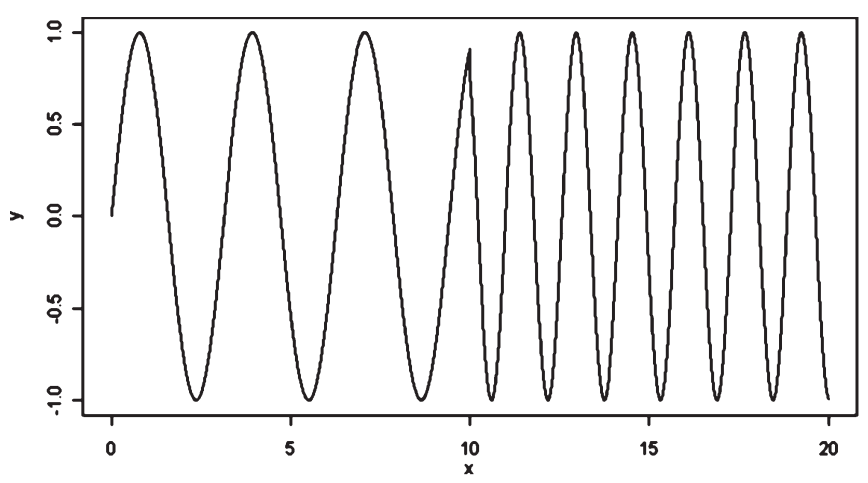

Fig. 2 Signal with two different periods (the first ends at $t=10$, when the second starts). pothesis for the significance of a peak in the wavelet power spectrum (Torrence and Compo, 1998).

\section{a. Fourier and wavelet red noise spectrum}

Many time series can be modeled as white or red noise. A simple model for red noise is the unvariate lag-1 autoregressive [AR(1) or Markov] process:

$$
x_{n}=\alpha x_{n-1}+z_{n}
$$

Where is the assumed lag-1 autocorrelation, , and is taken from the Gaussian white noise. Following Gilman et al. (1963), the discrete Fourier power spectrum of (5), after normalizing, is:

$$
P_{k}=\frac{1-\alpha^{2}}{1+\alpha^{2}-2 \alpha \cos \left(\frac{2 \pi k}{N}\right)}
$$

where $k=0 \ldots N / 2$ is the frequency index. Thus, by choosing an appropriate lag-1autocorrelation, one can use (6) to model a red-noise spectrum. Note that $\alpha=0$ in (6) gives a white-noise spectrum.

The wavelet transform is a series of band-pass filters of the time series. If this time series can be modeled as a lag-1 AR process, then it seems reasonable that the local wavelet power spectrum, which is defined as a vertical slice, is given by (6).

\section{b. Significance levels}

The null hypothesis is defined for the wavelet power spectrum as follows: It is assumed that the time series has a mean power spectrum, possibly given by (6); if a peak in the wavelet power spectrum is significantly above this background spectrum, then it can be assumed to be a true feature with a certain percent of confidence. For definitions significant at the $5 \%$ level it is equivalent to the $95 \%$ confidence level and implies a test against a certain background level, while the $95 \%$ confidence interval refers to the range of confidence about a given value.

\section{c. Confidence interval}

The confidence interval can be defined as the probability that the true wavelet power at a certain time and on a certain scale lies within a certain interval around the estimated wavelet power. In the formula

$$
\frac{\left|W_{n}(s)\right|^{2}}{\sigma^{2} P_{k}} \Rightarrow \frac{\chi_{2}^{2}}{2}
$$

it can replace the theoretical wavelet power $\sigma^{2} P_{k}$ with the true wavelet power, defined as $W_{n}^{2}(s)$. The confidence interval for $W_{n}^{2}(s)$ is then:

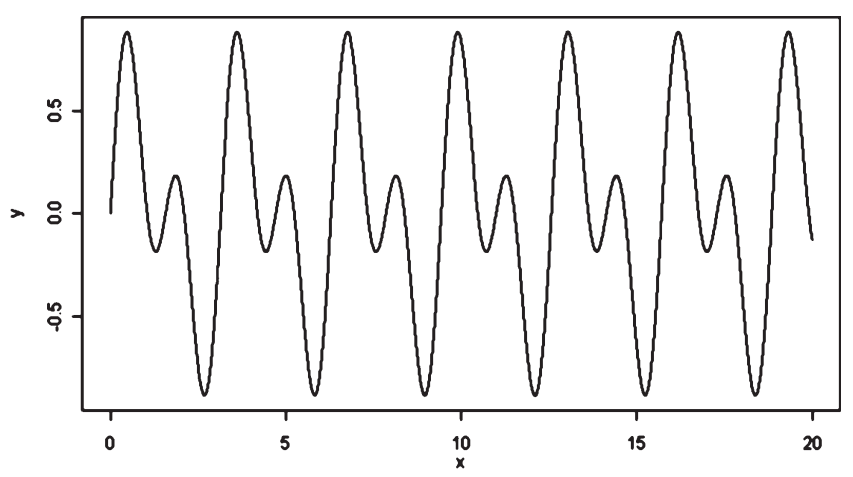

Fig. 3 Signal with two different periods (both present during the whole time range). 


$$
\frac{2}{\chi_{2}^{2}\left(\frac{p}{2}\right)}\left|W_{n}(s)\right|^{2} \leq W_{n}^{2}(s) \leq \frac{2}{\chi_{2}^{2}\left(1-\frac{p}{2}\right)}\left|W_{n}(s)\right|^{2}
$$

Where $p$ is the desired significance ( $p=0.05$ for the $95 \%$ confidence interval), and $\chi_{2}^{2}\left(\frac{p}{2}\right)$ represents the value of $x^{2}$ at $\left(\frac{p}{2}\right)$ (Torrence and Compo, 1998).

\section{DATA}

The input data in an annual step were used in this study. The input data consisted of the average annual discharges recorded at the Chalmová gauging station and the average annual air temperature and average annual precipitation recorded at the Hurbanovo gauging station. In this paper, the authors wanted to show that the WT and FA techniques belong among universal methods and can be used for various hydrological and meteorological data (e.g., discharges, air temperatures, precipitation). The authors intentionally chose data that are unrelated (integral data with point observations), because these data possessed quality and were representative, and the aim of this paper was only to test each of these methods and show the differences between them (this means we wanted to present some features and results that make WT a more suitable method compared to FA for the modeling of a structure of a time series). For a more detailed illustration using the hydroTSM (Zambrano - Bigiariny, 2014) package, we showed the graphs of the modeled time series (Figs. 4, 5, 6). The graphs provide information about the course and duration of the time series, information about the variability of the time series (minimum, maximum, 1 and 3 quantiles, median), and also information about the distribution of the time series.
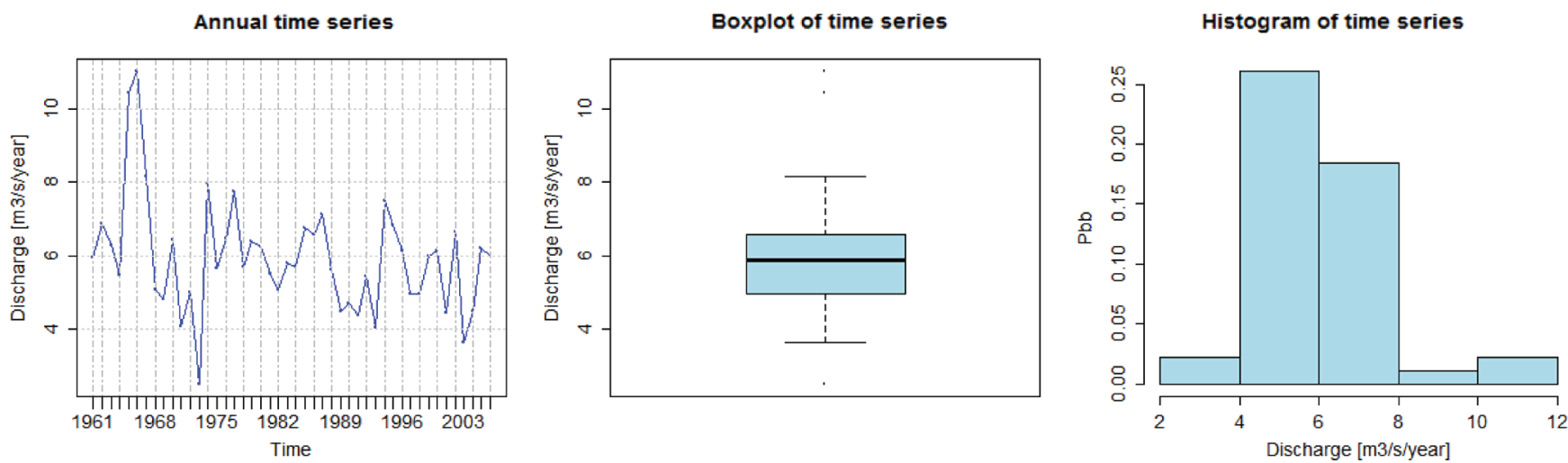

Fig. 4 Graphs of the average annual discharges at Chalmová.
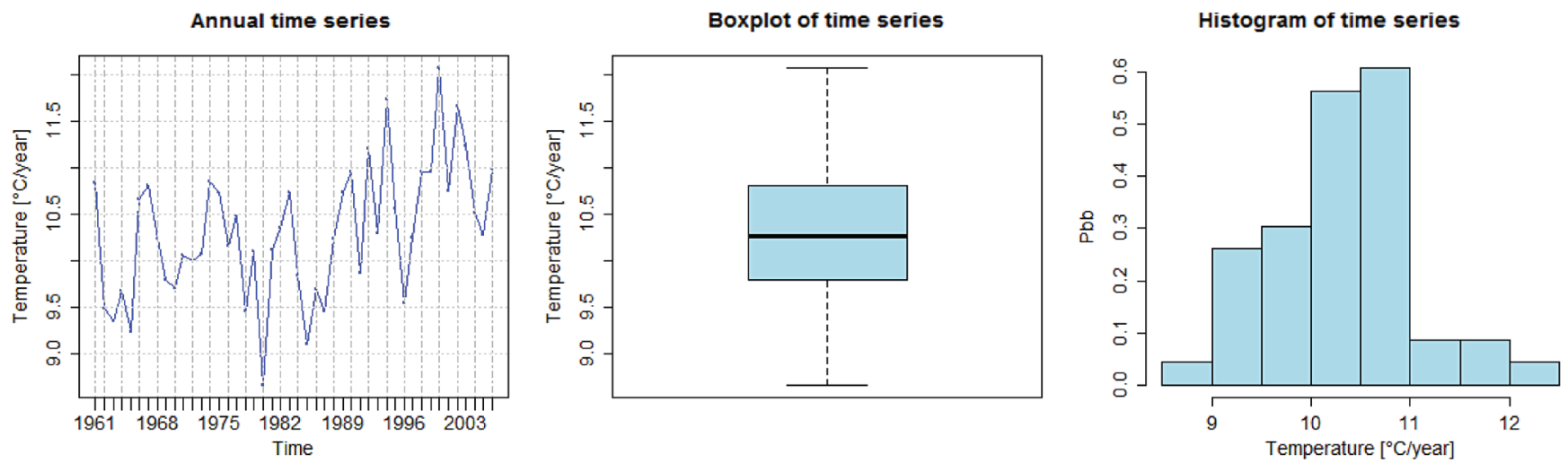

Fig. 5 Graphs of the average annual air temperatures at Hurbanovo.
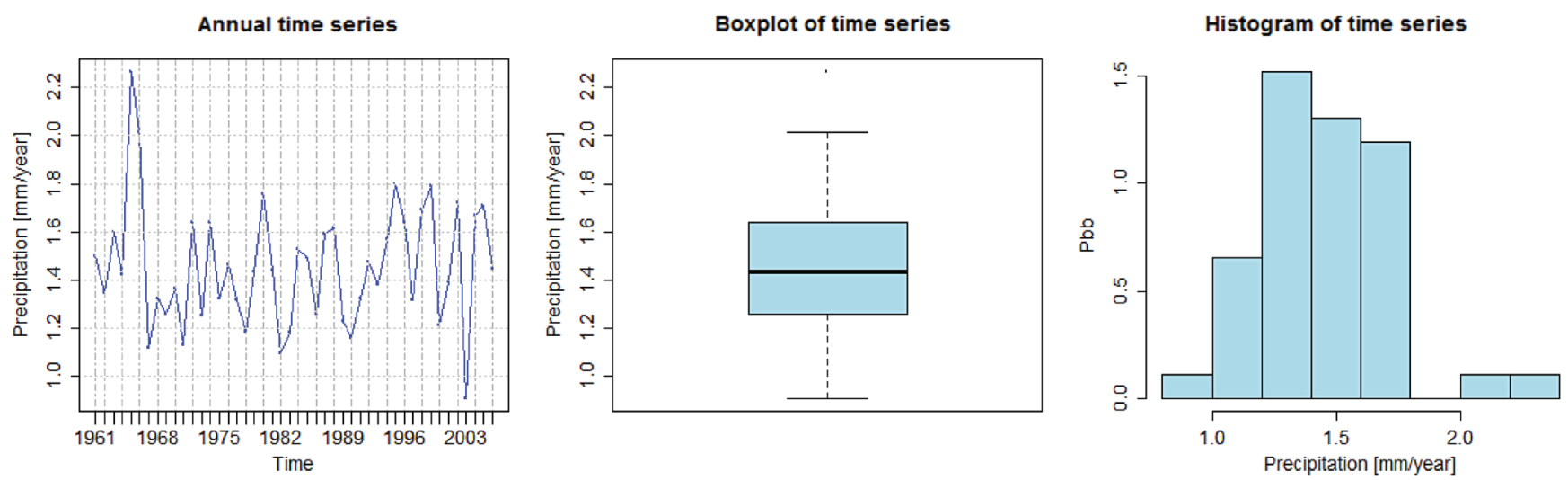

Fig. 6 Graphs of the average annual precipitation at Hurbanovo. 


\section{RESULTS}

The first three figures (Figs. 7, 8, and 9) provide information about the Fourier analysis. For a visualization of FA a periodogram is used. A periodogram is an estimator of the spectrum of a time series, where intensities of the angular frequencies are plotted and resemble "tiny lollipops".

For the modeling the average annual discharges recorded at the Chalmová gauging station during the years $(1961$ - 2006) (Fig. 7) were the first used. According to the periodograms, we can only identify the individual periods of the cyclic components, not their positions over time. We can see an approximately significant 12 -year period.

The second figure (Fig. 8) gives information about the air temperature at Hurbanovo $(1961-2006)$. We can identify an approximately significant 6.5 -year period.

The third figure models the precipitation recorded at the Hurbanovo gauging station during the years $1961-2006$ (Fig. 9). We can see an approximately significant 3.2-year period.

The next figures (Figs. 10, 11, and 12) provide information about the wavelet transform. The first figure (Fig. 10) gives information about the average annual discharges recorded at the Chalmová gauging station during the years $1961-2006$ (Fig. 10). We can see significant periods in a range of $3-4$ years, which occurred between the years $1961-1970$. We can also identify significant periods in a range of 8 years, which lasted between $1961-1990$. By the year 1990, we can identify shorter periods in a range of $7-12$ years.

The second figure (Fig. 11) provides information about the air temperatures at Hurbanovo during the years $1961-2006$. We can see significant periods in a range of $6-7$ years, which appeared during the years $1961-2006$.

Next, the precipitation recorded at the Hurbanovo gauging station $(1961$ - 2006) (Fig. 12) was modeled. By the year 1973, we can identify periods in a range of $2-8$ years. We can also see significant periods in a range of $2-3$ years, which occurred during the years $1997-2006$.

The last figure (Fig. 13) sets out information about computing the wavelet and scaling coefficients. As an example, we only chose the discharges at Chalmová; the wavelet coefficients and scaling coefficients were plotted where $\mathrm{X}$ is the object of the class of the discrete wavelet transform (the average annual discharges in our case), $\mathrm{W}$ is a list with the elements of the wavelet coefficients, and $\mathrm{V}$ is a list with the elements of the scaling coefficients. This is an important part of WT and WC. According to this principle, we can compute the similarity of two time series in their frequency ranges; this means that, for example, we can use discrete wavelet transform for feature extractions from time series in order to cluster them.

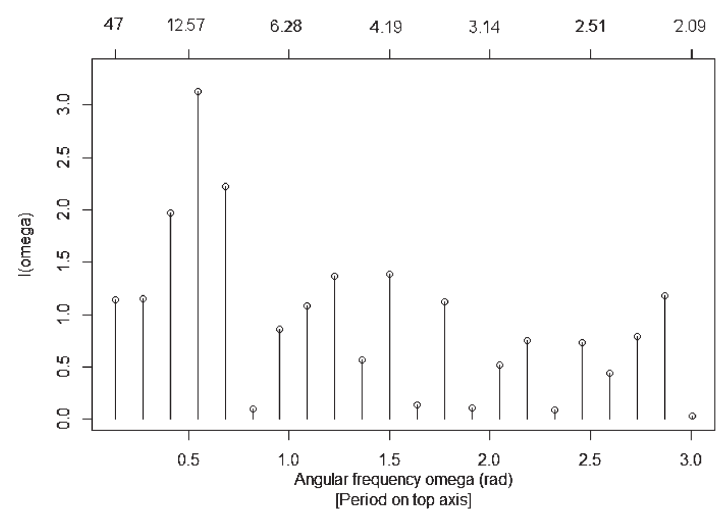

Fig. 7 Periodogram of the average annual discharges at Chalmová.

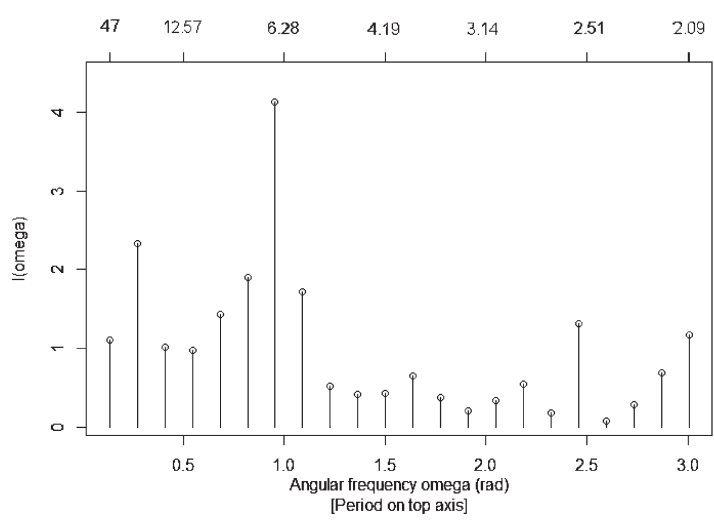

Fig. 8 Periodogram of the average annual air temperature at Hurbanovo.

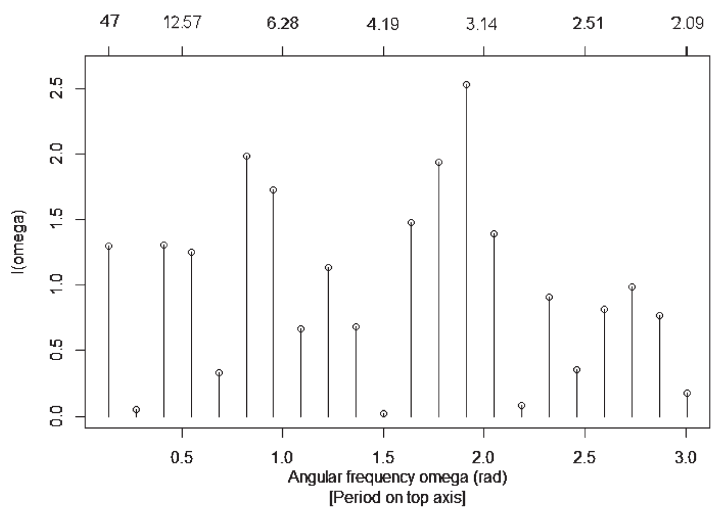

Fig. 9 Periodogram of the average annual precipitation at Hurbanovo.

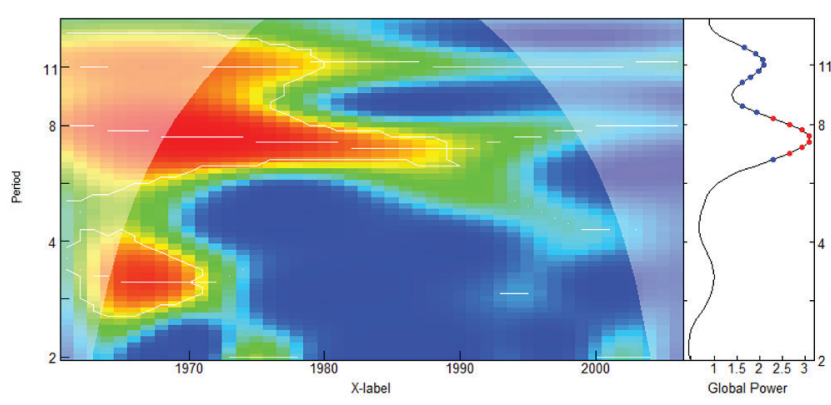

Fig. 10 Scalogram of the average annual discharges at Chalmová.

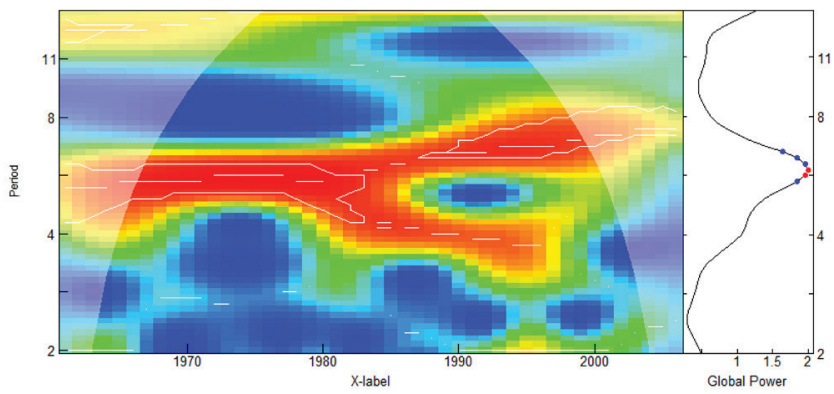

Fig. 11 Scalogram of the average annual air temperature at Hurbanovo. 


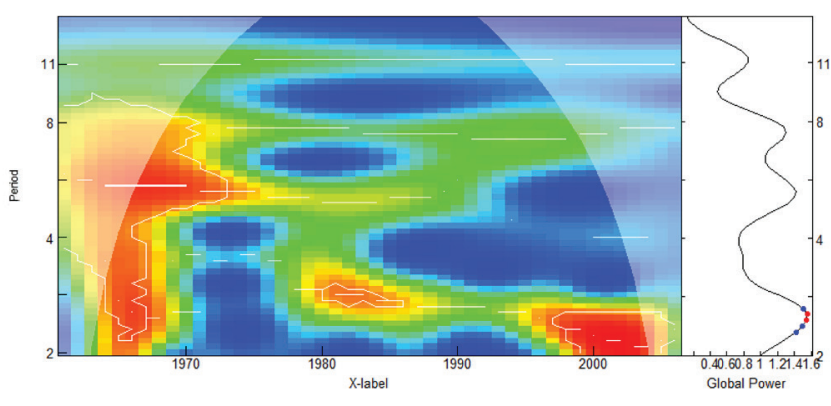

Fig. 12 Scalogram of the average annual precipitation at Hurbanovo.

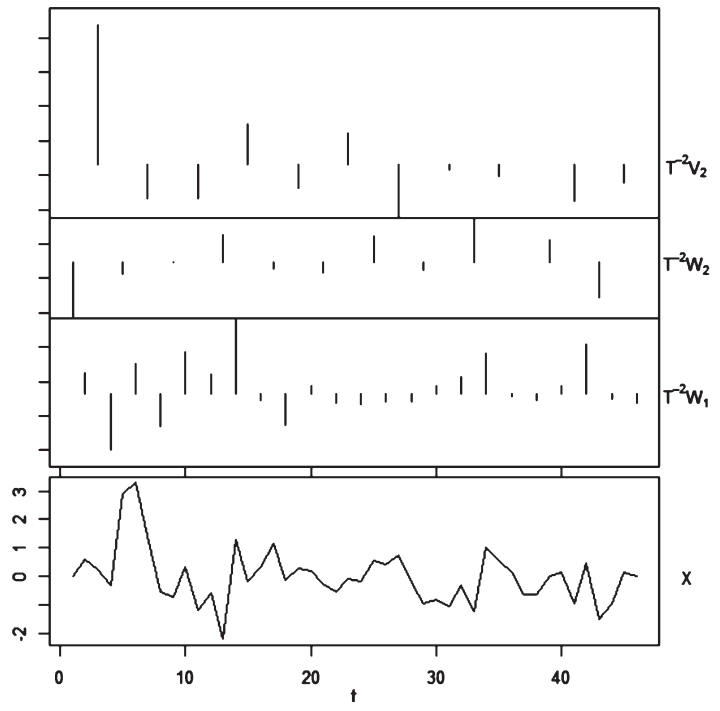

Fig. 13 Plot of the discrete wavelet transform - wavelet and scaling coefficients.

\section{DISCUSSION AND CONCLUSION}

Time series analysis is a major theme in stochastic hydrology that aims to reveal complicated hydrological processes. It is a very important task in practice as the basis of hydrological forecasting, simulations and many other water-related activities. A possible approach to solving this task is a detailed analysis of past periods. The processing of these data is based on new methods of statistical and mathematical analysis.

In this paper, the application of FA and WT to hydrological and climatological time series is demonstrated. The process of decomposing a function into simpler parts is called Fourier analysis. The decomposition process itself is called Fourier transform. WT is a universal mathematical method, which is able to work with non-stationary time series and is also able to detect when significant periods and their changes have been presented. In the first part, FA and WT are defined. In the practical part, these methods are used for the analysis of the average annual discharges at Chalmová and the average annual air temperature and precipitation at Hurbanovo.

The results show more significant cyclical components have been identified. According to the periodograms obtained from the Fourier transform of the time series (Figs. 7, 8, and 9), this method shows two major disadvantages. The first disadvantage is that the method assumes that the signal is stationary over time; this means that over that time, its properties do not change. The second is that it can only identify the individual periods of the cyclical components, not their positions over time (this means that this method is not able to detect when significant periods are present), despite the fact that the periodograms identified approximately similar periods as the WT method did (12-year period, 6.5-year period, 3.2-year period). On the contrary, wavelet transform deals with both problems in a very effective way. It is able to work with non-stationary time series and also to detect when significant periods are presented.

It is important to note that with both methods, we identified approximately similar periods, but determined their position over time only using WT. More significant cyclical components were identified. According to Fig. 10, which gives information about the average annual discharges at Chalmová, we observed significant periods in a range of 8 years, which lasted between 1961 - 1990. By the year 1990 , we can identify shorter periods in a range of $7-12$ years. Information about the air temperatures at Hurbanovo (Fig. 11) showed significant periods in a range of $6-7$ years, which appeared during 1961 - 2006. Information about the precipitation recorded at the Hurbanovo gauging station (Fig. 12) showed significant periods in a range of $2-3$ years, which occurred during the years $1997-2006$. By the year 1973, we can identify periods in a range of $2-8$ years.

The results showed that the WT method is more appropriate than FA for a time series analysis. As a result, we recommend WT for all time series with assumed periodic components (hydrology, climatology, EEG analysis)

\section{Acknowledgements}

This work was supported by the Slovak Research and Development Agency under Contract Nos. APVV-0496-10 and APVV-030311 and VEGA 1-0776-13. 


\section{REFERENCES}

Aldrich, E. (2013) Wavelets: A package of functions for computing wavelet filters, wavelet transform and multiresolution analyses. $\mathrm{R}$ package version $0.3-0$.

Biswas, A. (2014) Landscape characteristics influence the spatial pattern of soil water storage: Similarity over times and at depths. Catena 116. 68-77.

Bloomfield, P. (2000) Fourier analysis of time series: An introduction. 2nd ed., 288, ISBN 04711889482

Brázdil, R. (1986) Kolísání ráad srážek a průtoků na území ČSSR ve vztahu ke kolísání slunečni aktivity. (Fluctuations of rainfall and discharges in the ĆSSR in relation to the fluctuations in solar activity) In: Study SHMÚ 1986, 36, 7-27 (in Czech).

Briggs, W. L. - Henson, V. E. (1995) An owner's manual for the discrete Fourier transform. SIAM books, Philadelphia.

Cazelles, B. - Chavez, M. - Berteaux, D. - Ménard, F. - Vik, J. O. - Jenouvrier, S. - Stenseth, N. C. (2008) Wavelet analysis of ecological time series. Oecologica, 156 (2), 287-304.

Daubechies, I. - Mallat, S. - Willsky, A. (1992) Introduction to the special issue on wavelet transforms and multiresolution signal analysis. IEEE Transactions on Information Theory 38 (2), 528-531.

Feng, L. - Shenliang, Ch. - Jun, P. - Guangquan, Ch. (2011) Temporal variability of water discharge and sediment load of the Yellow River into the sea during 1950-2008. J. Geogr. Sci. 2011, 21(6), 1047-1061

Grinsted, A. - Moore, C. J. - Jevrejeva, S. (2004) Application of the cross wavelet transform and wavelet coherence to geophysical time series. Nonlinear Processes in Geophysics 11, 561-566.

Junger, W. - Ponce de Leon, A. (2011) pgam: Poisson-Gamma Additive Models. R package version 0.4.11.

Kumar, P. - Foufoula - Georgoiu, E. (1997) Wavelet analysis for geophysical applications. Reviews of Geophysics 35 (4), $385-412$

Labat, D. - Ababou R. - Mangin A. (2001) Introduction of wavelet analyses to rainfall/runoffs relationships for a carstic basin: The case of Licq-Atherey karstic system France, Ground Water, 39(4), 605-615.

Labat, D. (2005) Recent advances in wavelet analyses: Part 1 - A review of concepts. J. Hydrol. 314, 289-311.

Labat, D. (2006) Oscillations in land surface hydrological cycle. Earth Planet. Sci. Lett. 242, 143-154.

Labat, D. (2008) Wavelet analysis of the annual discharge records of the world's largest rivers. Adv. Water Resour. 31, 109-117.

Li, L. - Qian, J. - Ou, Q-Ch. - Zhou, X-Y. - uo, C. - Guo, Y. (2014) Spatial and temporal analysis of Air Pollution Index and its timescale-dependent relationship with meteorological factors in Guangzhou, China, 2001-2011. Environmental Pollution, 75-81.

Liu, T. L. - Hsu, T. H. - Grafarend, W. E. (2005) Wavelet coherence analysis of Length-Of-Day variations and El Nino-Southern Oscillation. Journal of Geodynamics 39., 267-275.
Mokhov, I. I. - Smirnov, A. D. - Karpenko, A. A. (2012) Assessments of the Relationship of Changes of the Global Surface Air Temperature with Different Natural and Anthropogenic Factors Based on Observations. ISSN 1028_334X, Doklady Earth Sciences, 2012, Vol. 443, Part 1, pp. 381-387.

Pekárová, P. (2000) Zákonitosti kolísania priemerných ročných prietokov. (Average annual discharge oscillation regularities). National Climate Program - Bratislava: SHMÚ: MŽP SR, No. 9, 39-57 (in Slovak).

Pekárová, P. - Miklánek, P. - Pekár, J. - Olbrímek, J. (2008) Analýza zmien štatistických charakteristík denných úhrnov zrážok na stanici Hurbanovo a v rôznych obdobiach Čast' I. Viacročná variabilita a spektrálna analýza. (Analysis of the statistical characteristics of daily precipitation at Hurbanovo in different periods: Part I. Multiannual variability - spectral analysis). Acta hydrologica Slovaca, 9, No. 1., 183-195 (in Slovak).

Prokoph, A. - Barthelmes, F. (1996) Detection of nonstationarities in geological time series: Wavelet transform of chaotic and cyclic sequences. Computers \& Geosciences Vol. 22, No. 10, pp. 1097-1108.

$\mathbf{R}$ development Core Team (2011) $R$ : A language and environment for statistical computing. R Foundation for Statistical Computing, Vienna, Austria. ISBN 3-900051-07-0, URL http:/www.R-project.org/.

Sabo, M. (2012) Ako analyzovat' časové rady pomocou wavelet transformácie (How to analyze time series with wavelet transform). Acta hydrologica Slovaca, 13, No. 1., 233-241 (in Slovak).

Sleziak, P. (2014) Analýza časových radov prietokov vybraných slovenských riek pomocou vlnkovej transformácie (Discharge time series analysis of selected Slovak rivers by wavelet transform). Acta hydrologica Slovaca, 15, No. 1., 171-177 (in Slovak).

Szolgayová, E. - Parajka, J. - Blöschl, G. - Bucher, C. (2013) Long term variability of the Danube River flow and its relation to precipitation and air temperature. Elsevier Editorial System(tm) for Journal of Hydrology, Manuscript Draft.

Szolgayová, E. - Arlt, J. - Blöschl, G. - Szolgay, J. (2014) Wavelet based deseasonalization for modelling and forecasting of daily discharge series considering long range dependence. J. Hydrol. Hydromech., (62)1, 24-32.

Tian, H. - Cazelles, B. (2011) WaveletCo: Wavelet Coherence Analysis. R package version http://CRAN.R-project.org/package=WaveletCo

Torrence, C. - Compo, G. P. (1998) A Practical Guide to Wavelet Analysis, Bulletin of the American Meteorological Society, 79(1), 61-78.

Zambrano - Bigiarini, M. (2014) Time series management, analysis and interpolation for hydrological modeling. $\mathrm{R}$ package version 0.4-2-1.

Zhang, D. - Hong, H. - Zhang, Q. - Li, X. (2014) Attribution of the changes in annual streamflow in the Yangtze River Basin over the past 146 years. Theor Appl Climatol. DOI 10.1007/s00704014-1121-3.

Weaver, J. (1989) Theory of Discrete and Continous Fourier Transform. New York: John Wiley \& Sons. 